\title{
Tingkat Fluktuasi Air Tanah pada Jangka Pendek di Kecamatan Ngemplak, Kabupaten Sleman, Provinsi Daerah Istimewa Yogyakarta
}

\author{
Short-term Level of Groundwater Fluctuation in Ngemplak District, \\ Sleman Regency, Special Region of Yogyakarta
}

\author{
SADEWA PURBA SEJATI \\ Program Studi Geografi, Universitas Amikom Yogyakarta, Jl. Ringroad Utara, Condong Catur, Depok, Sleman, Yogyakarta \\ Email: sadewa@amikom.ac.id
}

\begin{abstract}
Water is a natural resource used by people for various life necessities. The type of water often used by people is groundwater. Groundwater conditions should be inventoried to protect and maintain the continued function of groundwater. The research area was the administrative area of the Ngemplak Subdistrict in Sleman Regency. Construction, growing population, and changing system positively correlate with potential disturbance to quantity, quality, and distribution of groundwater in the research area. To anticipate this, changing groundwater conditions in the administrative area of the Ngemplak Sub-district should be determined. The present study was aimed to determine the changing condition or dynamics of groundwater in the administrative area of Ngemplak Sub-district. The parameter used in the present study was the level of groundwater fluctuation. The primary data of groundwater depth in rainy and dry seasons 2019 was collected using a systematic random sampling method. Groundwater surface fluctuation data was obtained from the difference in groundwater-surface depths in dry and rainy seasons. The level of groundwater fluctuation was analyzed using the spatial interpolation method and classified using ArcGIS. The research result showed that the level of groundwater fluctuation in the research area consisted of three classes, i.e., low ( $<2.5$ meters), medium (2.5 - 5 meters), and high ( $>5$ meters). The research area was dominated by medium groundwater fluctuation. Spatial data analysis showed that groundwater fluctuation in the research area wasn't only affected by reduced groundwater supply due to changing seasons but also by the massive groundwater usage.
\end{abstract}

Keywords: groundwater, fluctuation, spatial interpolation

\begin{abstract}
ABSTRAK
Air merupakan sumberdaya alam yang digunakan penduduk untuk memenuhi beragam kebutuhan hidup. Jenis air yang seringkali digunakan penduduk adalah air tanah. Inventarisasi kondisi air tanah perlu dilakukan sebagai upaya untuk menjaga dan mempertahankan keberlanjutan fungsi air tanah. Wilayah yang menjadi perhatian dalam penelitian ini adalah wilayah Kecamatan Ngemplak, Kabupaten Sleman. Pembangunan, peningkatan jumlah penduduk, dan peralihan musim berkorelasi positif dengan munculnya potensi gangguan terhadap kuantitas, kualitas, dan distribusi air tanah di daerah penelitian. Untuk mengantisipasi hal tersebut maka perubahan kondisi air tanah di wilayah Kecamatan Ngemplak perlu diketahui. Penelitian ini bertujuan untuk mengetahui perubahan kondisi atau dinamika air tanah di wilayah administratif Kecamatan Ngemplak. Parameter yang digunakan dalam penelitian ini adalah tingkat fluktuasi air tanah. Data primer kedalaman air tanah pada musim hujan dan kemarau tahun 2019 dikumpulkan dengan metode systematic random sampling. Data fluktuasi air tanah merupakan selisih dari kedalaman air tanah pada musim kemarau dengan musim hujan. Tingkat fluktuasi air tanah dianalisis menggunakan metode interpolasi spasial dan klasifikasi dengan perangkat lunak ArcGIS. Hasil penelitian menunjukkan bahwa tingkat fluktuasi air tanah di daerah penelitian diklasifikasikan menjadi tiga kelas, yaitu rendah ( $<2,5$ meter), sedang $(2,5-5$ meter), dan tinggi ( $>5$ meter). Daerah penelitian didominasi oleh fluktuasi air tanah pada tingkat sedang. Analisis data spasial menunjukkan bahwa fluktuasi air tanah di daerah penelitian tidak hanya dipengaruhi berkurangnya suplai air tanah akibat perubahan musim, tetapi juga diakibatkan penggunaan air tanah dalam jumlah yang besar.
\end{abstract}

Kata kunci: air tanah, fluktuasi, interpolasi spasial

\section{PENDAHULUAN}

\subsection{Latar Belakang}

Air merupakan sumberdaya alam yang digunakan penduduk untuk memenuhi beragam kebutuhan hidup. Jenis air yang seringkali digunakan penduduk adalah air tanah. Penduduk sangat bergantung pada air tanah untuk memenuhi beragam kebutuhan, seperti minum, memasak, mandi, dan mencuci(1). Air 
tanah digunakan sebagai sumber untuk memenuhi kebutuhan penduduk karena berbagai kelebihan yang dimilikinya. Salah satu kelebihan air tanah jika dibandingkan dengan air permukaan (air sungai, laut, danau, dan situ) adalah air tanah relatif lebih bersih. Keberadaan air tanah pada zona akuifer menjadikannya lebih terlindung dari polutan ${ }^{(2-4)}$.

Berdasarkan konsep siklus air (water cycle), air tanah termasuk sumber daya alam yang dapat diperbarui. Siklus air menyebabkan kuantitas air tanah di bumi dalam keadaan tetap atau statis ${ }^{(5,6)}$. Air tanah dari segi kuantitasnya dapat dikatakan statis, namun distribusi dan kualitasnya bersifat dinamis. Dinamika air tanah dapat dipengaruhi oleh variasi kondisi geografis, aktivitas alam, maupun aktivitas manusia. Peralihan musim dan perubahan penggunaan lahan seringkali disebut sebagai faktor yang mempengaruhi dinamika air tanah ${ }^{(7)}$. Dinamika air tanah berpotensi menyebabkan ketidakselarasan antara kuantitas, kualitas, dan distribusi air tanah. Ketidakselarasan tersebut menyebabkan manfaat air tanah tidak dapat dirasakan secara merata oleh penduduk yang tersebar di berbagai wilayah, dengan kata lain fungsi air tanah sebagai sumber yang dapat digunakan untuk memenuhi kebutuhan penduduk mengalami gangguan. Permasalahan yang berkaitan dengan kuantitas, kualitas, dan distribusi air tanah banyak ditemukan pada sebagian wilayah di Kabupaten Sleman dan sekitarnya $^{(8-11)}$.

Inventarisasi kondisi air tanah perlu dilakukan sebagai upaya untuk menjaga dan mempertahankan keberlanjutan fungsi air tanah(12). Inventarisasi kondisi air tanah melalui penelitian lebih banyak berfokus pada kondisi sesaat. Penelitian yang dilakukan untuk mengetahui perubahan kondisi air tanah belum banyak dilakukan. Perubahan kondisi air tanah merupakan informasi penting yang dapat digunakan sebagai dasar pengelolaan dan perlindungan air tanah ${ }^{(13,14)}$. Pengelolaan dan perlindungan air tanah dilakukan untuk menjaga kelestarian air tanah agar dapat memberikan manfaat bagi penduduk secara berkelanjutan.

Wilayah yang menjadi perhatian dalam penelitian ini adalah wilayah Kecamatan Ngemplak, Kabupaten Sleman. Berdasarkan pengolahan data diketahui bahwa dalam kurun waktu sembilan tahun (2006 hingga 2015) telah terjadi perubahan penggunaan lahan dari lahan tidak terbangun menjadi lahan terbangun. Luas lahan terbangun bertambah 235,58 hektar pada tahun 2015. Pembangunan, peningkatan jumlah penduduk, dan peralihan musim berkorelasi positif dengan munculnya gangguan terhadap kuantitas, kualitas, dan distribusi air tanah. Perubahan kondisi air tanah di Kecamatan
Ngemplak perlu diketahui untuk mengantisipasi permasalahan air tanah.

\subsection{Tujuan Penelitian}

Berdasarkan uraian pada bagian latar belakang, penelitian ini bertujuan untuk mengetahui perubahan kondisi atau dinamika air tanah di wilayah Kecamatan Ngemplak, Kabupaten Sleman. Parameter yang digunakan dalam penelitian ini adalah fluktuasi air tanah. Hasil penelitian berupa tingkat fluktuasi air tanah di wilayah Kecamatan Ngemplak, Kabupaten Sleman. Hasil penelitian divisualkan menggunakan teknologi Sistem Informasi Geografis (SIG). Hasil dari penelitian ini diharapkan dapat dijadikan sebagai masukan dalam pengelolaan dan perlindungan air tanah di wilayah Kecamatan Ngemplak, Kabupaten Sleman, Provinsi Daerah Istimewa Yogyakarta.

\section{BAHAN DAN METODE}

\subsection{Bahan}

Penelitian dilakukan di wilayah Kecamatan Ngemplak, Kabupaten Sleman, Provinsi Daerah Istimewa Yogyakarta. Kecamatan Ngemplak terbagi menjadi lima desa. Peta administrasi daerah penelitian dapat dilihat pada Gambar 1. Data yang digunakan dalam penelitian ini adalah data primer kedalaman air tanah pada periode musim hujan dan musim kemarau tahun 2019. Data kedalaman air tanah pada musim hujan dan kemarau dikumpulkan untuk mengetahui perubahan kedalaman air tanah. Sumur gali dijadikan sebagai objek pengumpulan data kedalaman air tanah.

Pengukuran kedalaman air tanah dilakukan dengan memasukan pita ukur dari bibir sumur hingga menyentuh permukaan air tanah. Hasil pembacaan terhadap pita ukur kemudian dicatat. Lokasi sumur yang digunakan untuk melakukan pengukuran ditentukan menggunakan sampel. Metode penentuan sampel yang digunakan dalam penelitian ini adalah systematic random sampling. Metode tersebut dipilih agar diperoleh sampel yang merata pada seluruh daerah penelitian ${ }^{(16,17)}$. Grid-grid semu dengan ukuran 750 x 750 meter dibuat pada peta daerah penelitian, sampel kemudian ditentukan secara acak pada setip grid yang telah terbentuk. Posisi koordinat lokasi sampel juga dicatat. Posisi tersebut diketahui dengan Global Positioning System receiver (GPS receiver) tipe Garmin 64S yang memiliki akurasi 2 meter. Posisi koordinat diperlukan agar data dapat diolah menjadi informasi spasial. 


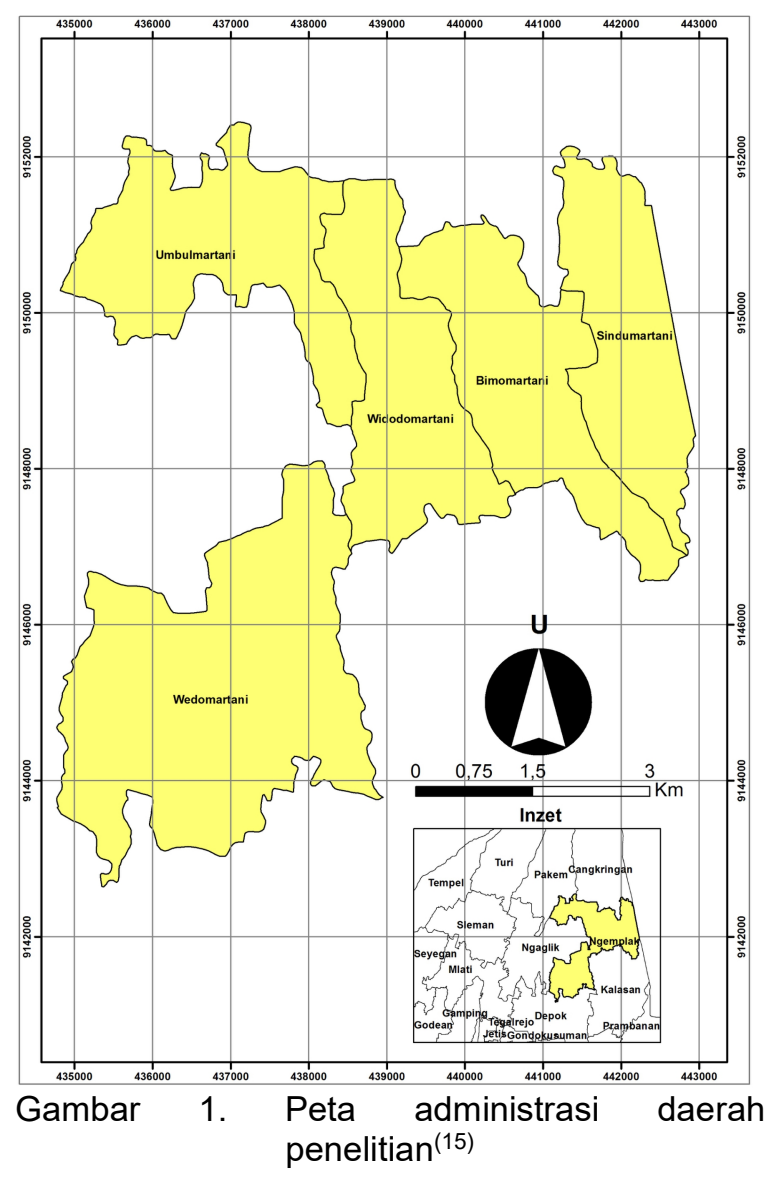

\subsection{Metode}

Sampel yang telah terkumpul memiliki dataset yang terdiri dari data posisi koordinat, data kedalaman air tanah musim hujan dan musim kemarau. Fluktuasi air tanah pada setiap sampel diketahui dengan persamaan sebagai berikut:

Fluktuasi air tanah $=$

Muka air tanah musim hujan (meter) muka air tanah musim kemarau (meter).

Setelah nilai fluktuasi muka air tanah pada setiap sampel diketahui, selanjutnya adalah melakukan analisis spasial yang berupa interpolasi. Interpolasi merupakan salah satu metode analisis spasial yang seringkali digunakan untuk menganalisis data dengan strutur titik (point) menjadi informasi yang berupa area ${ }^{(18-20)}$. Interpolasi dalam penelitian ini digunakan untuk mengetahui variasi keruangan fluktuasi air tanah di seluruh daerah penelitian. Proses interpolasi spasial dilakukan dengan perangkat lunak (software) ArcGIS 10.3.

Hasil interpolasi kemudian diklasifikasi untuk mengetahui tingkat fluktuasi air tanah di daerah penelitian. Tingkat fluktuasi air tanah di daerah penelitian diklasifikasikan menjadi 3 kelas, yaitu rendah, sedang, dan tinggi(18). Rincian klasfikasi fluktuasi air tanah dapat dilihat pada Tabel 1.
Secara skematis, diagram alir penelitian dapat dilihat pada Gambar 2.

Tabel 1. Klasifikasi tingkat fluktuasi air tanah ${ }^{(18)}$

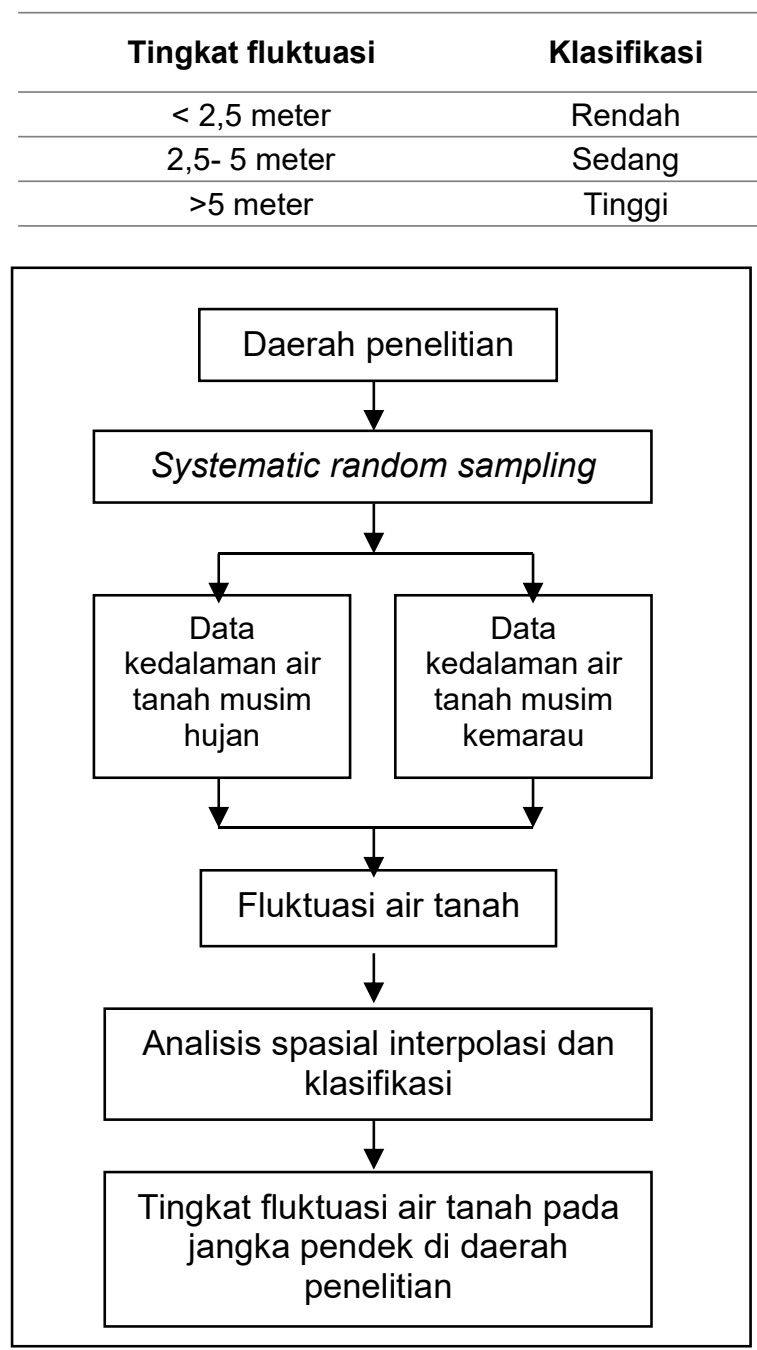

Gambar 2. Diagram alir penelitian

\section{HASIL DAN PEMBAHASAN}

\subsection{Kondisi Kedalaman Air Tanah pada Musim Hujan}

Kondisi air tanah pada musim hujan diketahui berdasarkan data primer kedalaman air tanah yang dikumpulkan pada bulan Maret 2019. Persebaran data muka air tanah pada musim hujan dapat dilihat pada Gambar 3.

Variasi kedalaman air tanah secara keruangan dan kewilayahan (Gambar 4) didapatkan dari proses interpolasi spasial terhadap data yang disajikan pada Gambar 3. Hasil menunjukkan bahwa kedalaman air tanah pada musim hujan di daerah penelitian didominasi oleh kedalaman kurang dari 3 meter. Persentase luasan wilayah kedalaman air tanah di daerah penelitian pada musim hujan dapat dilihat pada Gambar 5. 


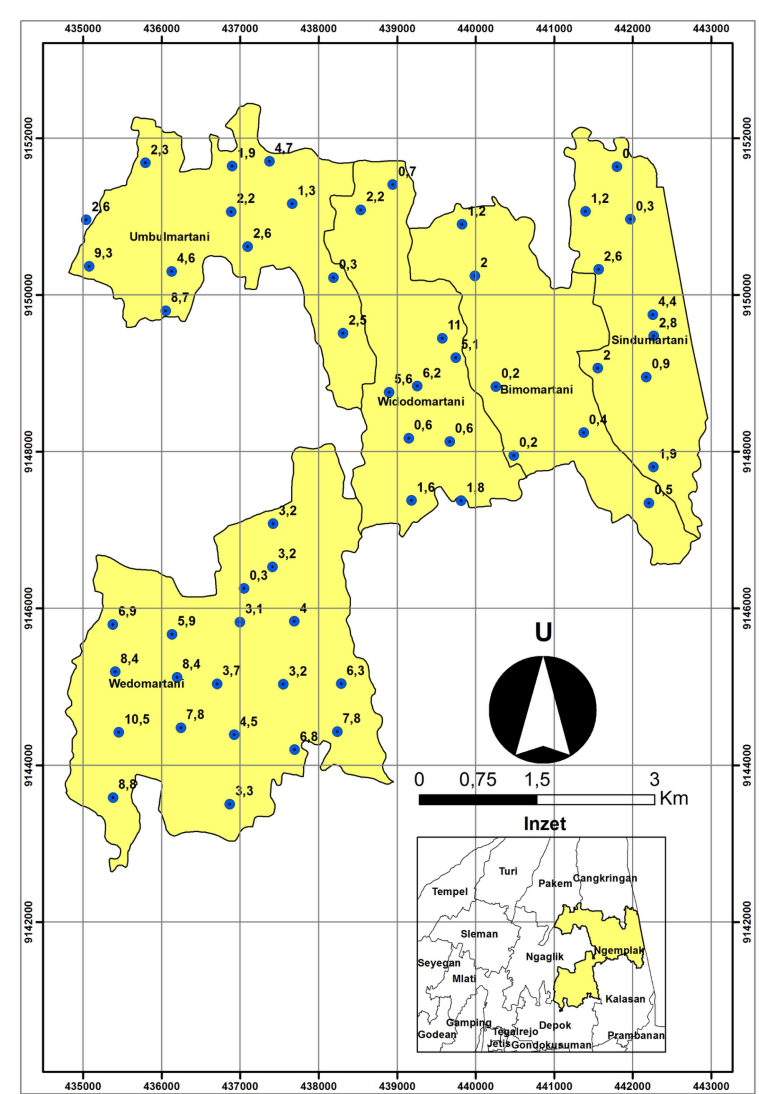

Gambar 3. Persebaran data kedalaman air tanah musim hujan

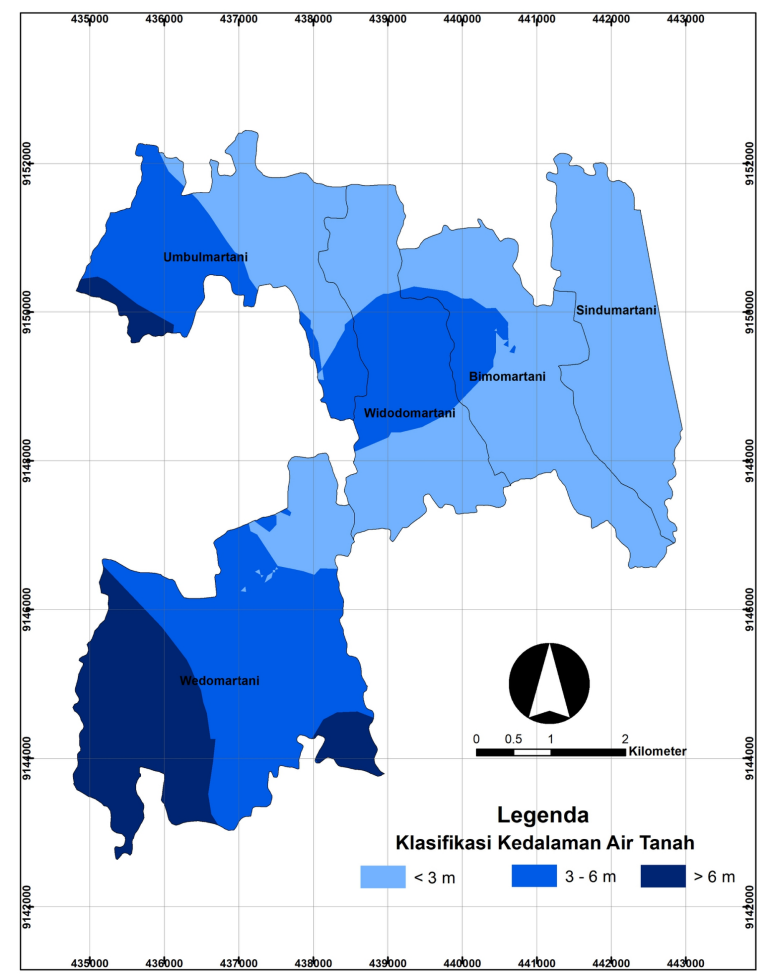

Gambar 4. Kondisi kedalaman air tanah pada musim hujan

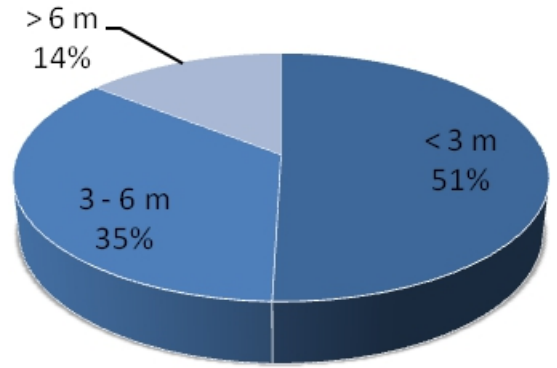

Gambar 5. Persentase kedalaman air tanah pada musim hujan

\subsection{Kondisi Kedalaman Air Tanah pada Musim Kemarau}

Kedalaman air tanah pada musim kemarau diidentifikasi berdasarkan data lapangan yang dikumpulkan pada bulan Oktober 2019. Persebaran data kedalaman air tanah di daerah penelitian dapat dilihat pada Gambar 6 .

Berdasarkan Gambar 7, air tanah musim kemarau di daerah penelitian didominasi oleh kedalaman lebih dari 6 meter. Persentase luasan wilayah kedalaman air tanah di daerah penelitian pada musim kemarau dapat dilihat pada Gambar 8.

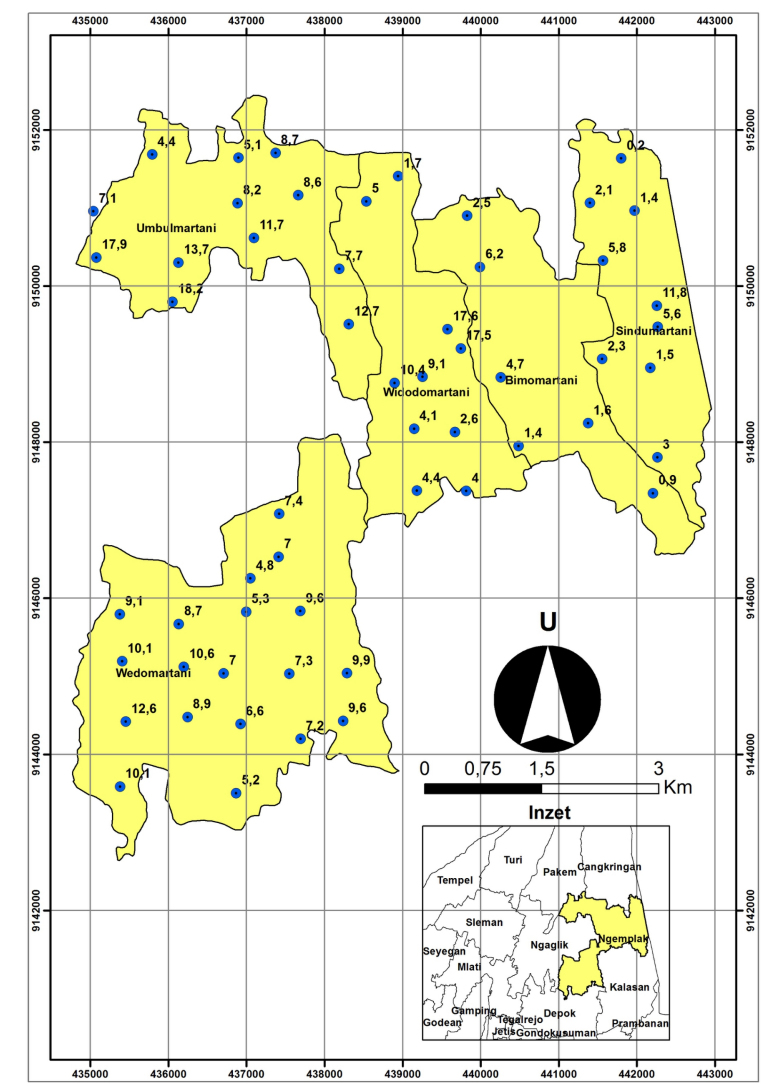

Gambar 6. Persebaran data kedalaman air tanah pada musim kemarau 


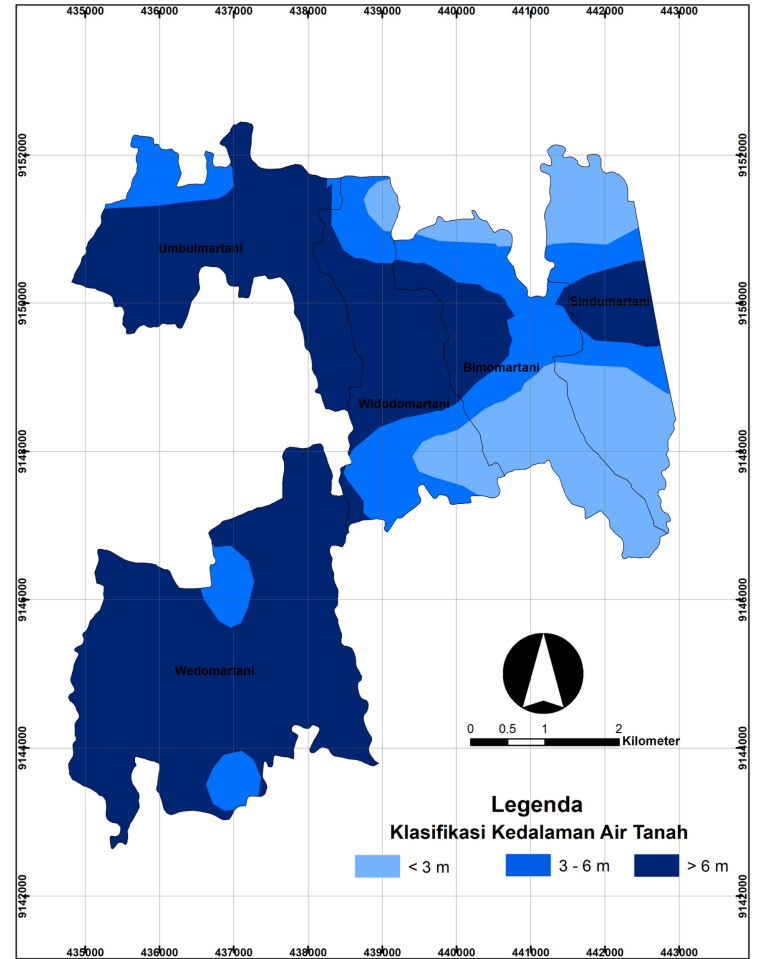

Gambar 7. Kondisi kedalaman air tanah pada musim kemarau

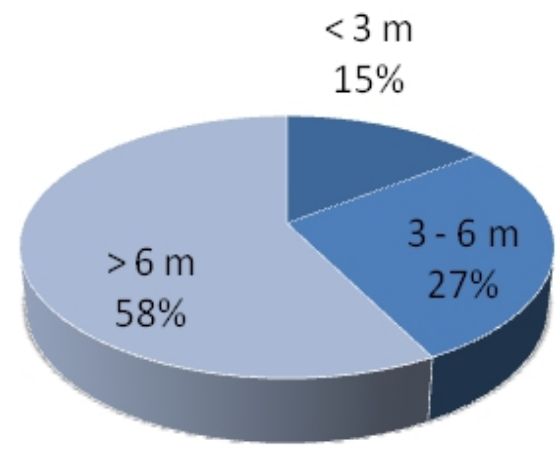

Gambar 8. Persentase kedalaman air tanah pada musim kemarau

\subsection{Tingkat Fluktuasi Air Tanah}

Penelitian ini berfokus pada fluktuasi muka air tanah jangka pendek. Pengamatan perubahan kedalaman air tanah hanya dilakukan pada satu periode musim, yaitu musim hujan dan musim kemarau tahun 2019. Bulan Maret 2019 dipilih untuk mengukur kedalaman air tanah pada musim hujan, sedangkan pengukuran di musim kemarau dilakukan pada bulan Oktober 2019. Berdasarkan hasil analisis yang telah disajikan dalam bentuk peta maupun diagram lingkaran pada sub bahasan sebelumnya, diketahui bahwa telah terjadi perubahan kedalaman air tanah seiring dengan terjadinya perubahan musim hujan menjadi musim kemarau di tahun 2019. Secara umum perubahan musim mengakibatkan perubahan kedalaman air tanah di daerah penelitian. Persentase perubahan luas area muka air tanah dapat dilihat pada Tabel 2.

Berdasarkan Tabel 2, dapat diketahui bahwa area dengan kedalaman air tanah lebih dari 6 meter mengalami peningkatan pada saat musim kemarau. Bertambah luasnya area dengan kedalaman air tanah lebih dari 6 meter tidak hanya disebabkan oleh faktor berkurangnya suplai air tanah pada musim kemarau, tetapi juga dipengaruhi oleh penggunaan lahan. Berdasarkan pengamatan data penginderaan jauh, diketahui bahwa area dengan kedalaman air tanah lebih dari 6 meter berada pada wilayah padat lahan terbangun berupa pemukiman dan fasilitas umum (Gambar 9 dan Gambar 10). Wilayah padat lahan terbangun terdapat di Desa Umbulmartani, Desa Widodomartani, dan Desa Wedomartani. Penggunaan air tanah yang masif pada wilayah pada tersebut dapat mempengaruhi kondisi muka air tanah menjadi lebih dalam.

Perbedaan kedalaman air tanah pada musim hujan dan musim kemarau kemudian digunakan untuk menentukan tingkat fluktuasi air tanah di daerah penelitian. Hasil analisis interpolasi spasial terhadap data fluktuasi air tanah pada dapat dilihat pada Gambar 11. Berdasarkan Gambar 11, tingkat fluktuasi air tanah di daerah penelitian diklasifikasikan menjadi tiga, yaitu tingkat fluktuasi rendah $(<2,5$ $\mathrm{m})$, tingkat fluktuasi sedang (2,5 hingga $5 \mathrm{~m})$ dan tingkat fluktuasi tinggi $(>5 \mathrm{~m})$. Persentase fluktuasi air tanah dapat dilihat pada Gambar 12.

Tabel 2. Perubahan luas wilayah kedalaman air tanah pada musim hujan dan musim kemarau

\begin{tabular}{ccccc}
\hline $\begin{array}{c}\text { Kedalaman Air } \\
\text { Tanah (meter) }\end{array}$ & $\begin{array}{c}\text { Persentase Luas } \\
\text { Wilayah pada Musim } \\
\text { Hujan (\%) }\end{array}$ & $\begin{array}{c}\text { Persentase Luas } \\
\text { Wilayah pada } \\
\text { Musim Kemarau } \\
(\%)\end{array}$ & Perubahan (\%) & Keterangan \\
\hline$<3 \mathrm{~m}$ & 50,4 & 14,8 & 35,7 & Berkurang \\
$3-6 \mathrm{~m}$ & 30,3 & 27,6 & 7,7 & Berkurang \\
$>6 \mathrm{~m}$ & 14,3 & 57,7 & 43,4 & Bertambah \\
\hline
\end{tabular}




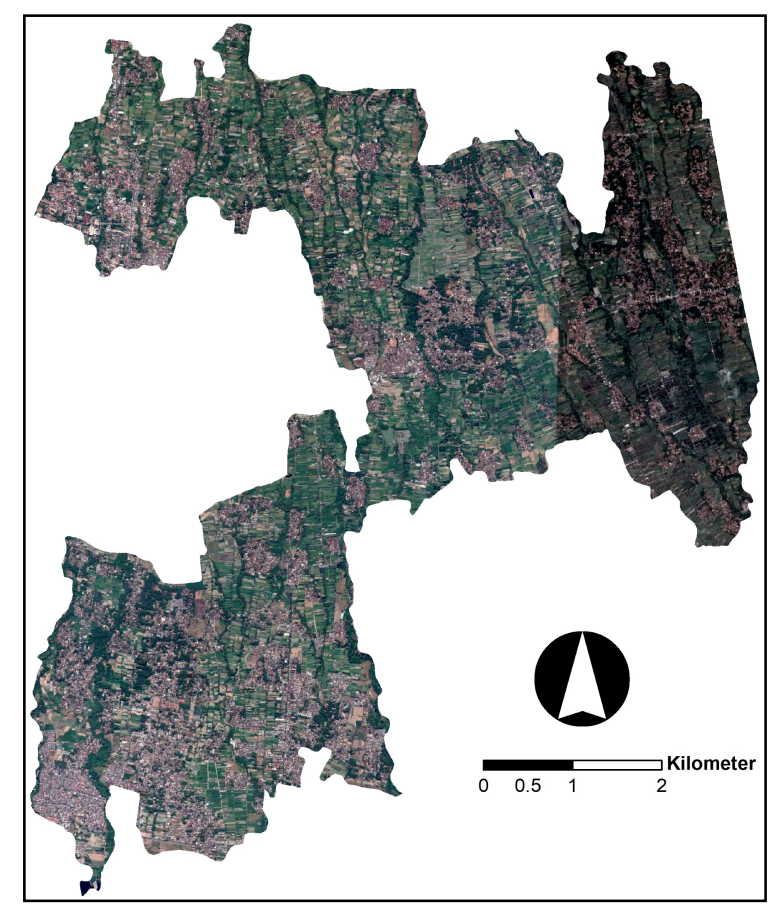

Gambar 9. Citra penginderaan jauh yang menunjukkan kondisi riil daerah penelitian, dalam citra ini dapat dilihat adanya lahan terbangun (berwarna kecokelatan) dan lahan yang tidak terbangun (berwarna hijau)

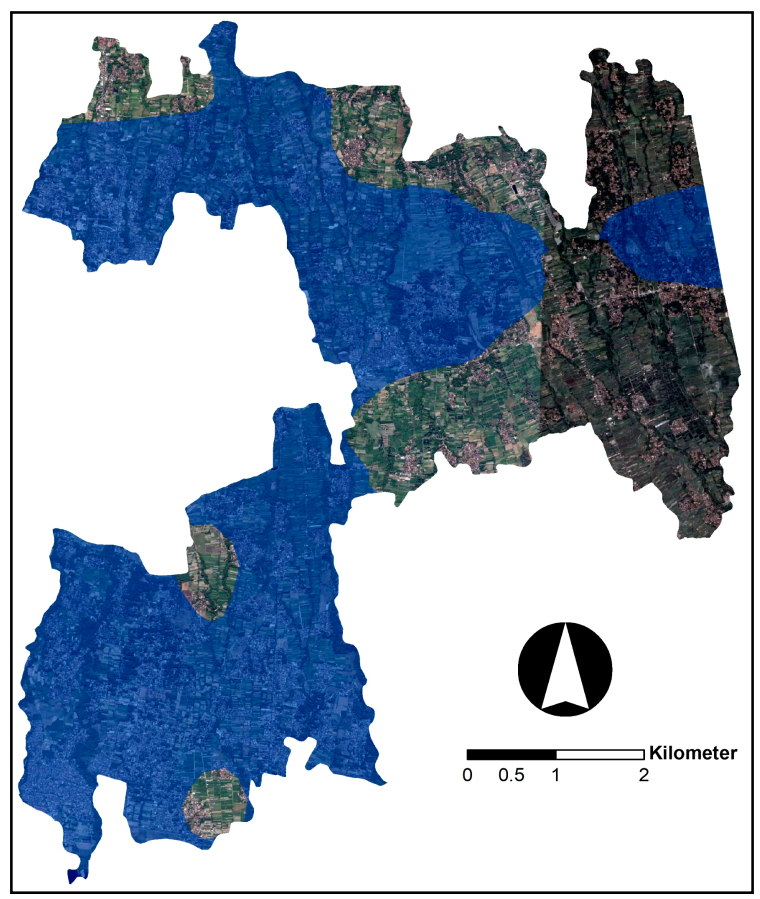

Gambar 10. Wilayah dengan kedalaman air tanah lebih dari 6 meter (ditandai dengan area berwarna biru) pada umumya terjadi di wilayah dengan kondisi lahan terbangun yang padat

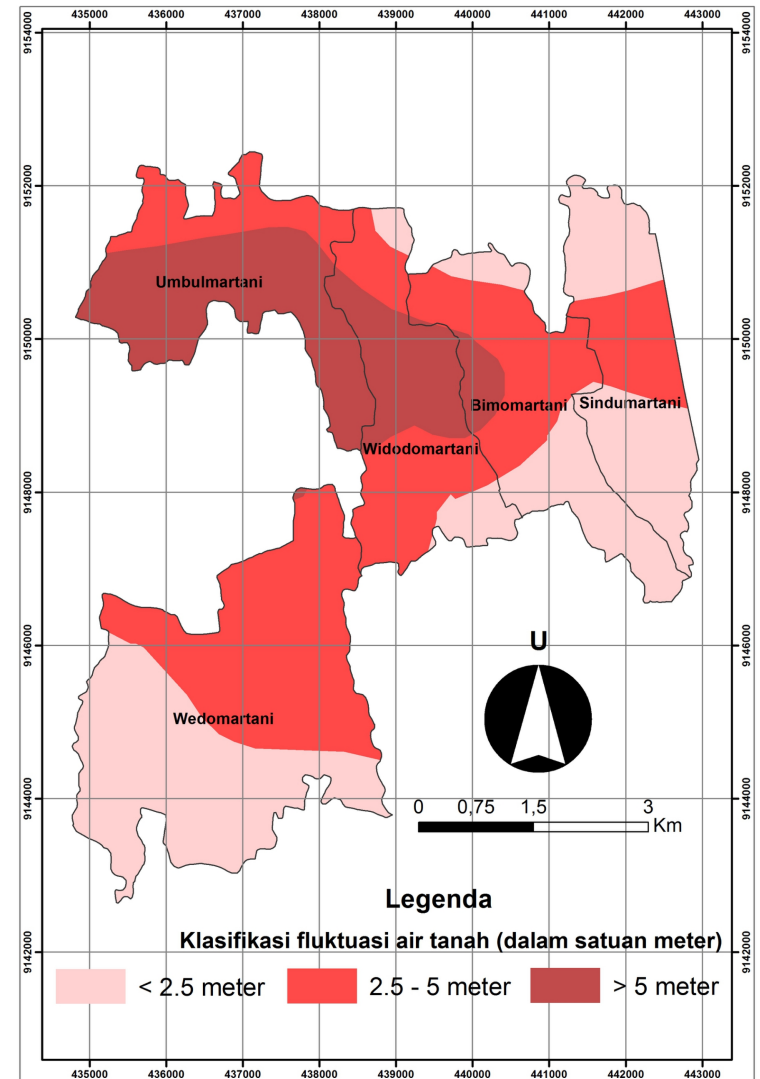

Gambar 11. Fluktuasi air tanah di daerah penelitian

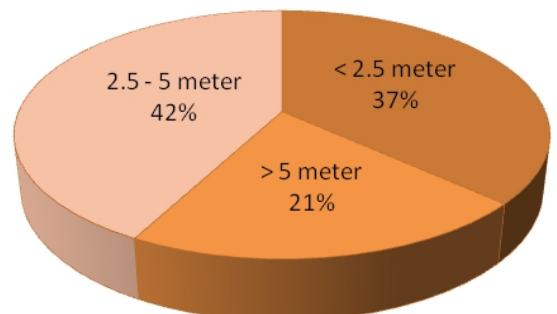

Gambar 12. Persentase fluktuasi air tanah di daerah penelitian

Berdasarkan Gambar 12, tingkat fluktuasi air tanah pada jangka pendek di daerah penelitian didominasi oleh tingkat sedang. Wilayah dengan tingkat fluktuasi sedang mengalami penurunan muka air tanah sebesar 2,5 hingga 5 meter saat musim kemarau. Persentase kedua ditempati oleh fluktuasi pada tingkat rendah. Wilayah pada fluktuasi tingkat rendah mengalami penurunan muka air tanah kurang dari 2,5 meter saat musim kemarau. Fluktuasi dengan tingkat tinggi menempati persentase luasan yang paling kecil. Wilayah dengan fluktuasi tinggi mengalami penurunan muka air tanah lebih dari 5 meter pada musim kemarau. Air tanah dengan fluktuasi tinggi terdapat di Desa Umbulmartani, Desa Widodomartani, dan Desa Bimomartani dengan persentase luas yang bervariasi. Air tanah 
dengan fluktuasi sedang dan rendah tersebar di daerah penelitian dengan persentase yang juga beragam. Rincian fluktuasi air tanah pada setiap desa dapat dilihat pada Tabel 3.

Tabel 3. Persentase tingkat fluktuasi air tanah

\begin{tabular}{|c|c|c|c|}
\hline Desa & Fluktuasi Tinggi & Fluktuasi Sedang & Fluktuasi Rendah \\
\hline Umbulmartani & $\begin{array}{l}73 \% \\
\text { Dusun Kali Dadap, Dusun } \\
\text { Nglanjaran, Dusun Kabul } \\
\text { Rejo, Dusun Nglempan, } \\
\text { Dusun Dongkel Sari, Dusun } \\
\text { Meces, Dusun Sapen, Dusun } \\
\text { Ngemplang, Dusun Ngasem }\end{array}$ & $\begin{array}{l}27 \% \\
\text { Dusun Kledokan, Dusun } \\
\text { Cilikan, Dusun Karang Turi }\end{array}$ & $0 \%$ \\
\hline Widodomartani & $\begin{array}{l}37 \% \\
\text { Dusun Pondok }\end{array}$ & $\begin{array}{l}48 \% \\
\text { Dusun Jetis, Dusun } \\
\text { Pucangan, Dusun Krigen, } \\
\text { Dusun Kemasan }\end{array}$ & $\begin{array}{l}15 \% \\
\text { Dusun Ngaliyan, Dusun } \\
\text { Blambangan }\end{array}$ \\
\hline Bimomartani & $\begin{array}{l}10 \% \\
\text { Dusun Cokrogaten }\end{array}$ & $\begin{array}{l}48 \% \\
\text { Dusun Pondoksuruh, Dusun } \\
\text { Jaten }\end{array}$ & $\begin{array}{l}42 \% \\
\text { Dusun Kali Bulus, Dusun } \\
\text { Mancasan, Dusun Ngelos } \\
\text { Karang }\end{array}$ \\
\hline Wedomartani & $0 \%$ & $\begin{array}{l}50 \% \\
\text { Dusun Karang Mojo, Dusun } \\
\text { Tegalsari, Dusun Pokoh, } \\
\text { Dusun Kepuh, Dusun } \\
\text { Wonosari, Dusun Saren } \\
\text { Kidul, Dusun Saren Lor, } \\
\text { Dusun Tegalan }\end{array}$ & $\begin{array}{l}50 \% \\
\text { Dusun Gandok, Dusun } \\
\text { Panjen, Dusun Karang Sari, } \\
\text { Dusun Jetis, Dusun Krajan, } \\
\text { Dusun Sono, Dusun } \\
\text { Bakungan, Dusun Kayen, } \\
\text { Dusun Sanggrahan, Dusun } \\
\text { Krapyak }\end{array}$ \\
\hline Sindumartani & $0 \%$ & $\begin{array}{l}30 \% \\
\text { Dusun Pokoh Baru, Dusun } \\
\text { Jamob, Dusun Kali Manggis }\end{array}$ & $\begin{array}{l}70 \% \\
\text { Dusun Manisan, Dusun } \\
\text { Tambakan, Dusun Kejambon } \\
\text { Lor, Dusun Plumbon, Dusun } \\
\text { Morangan }\end{array}$ \\
\hline
\end{tabular}

Di antara ketiga tingkat fluktuasi air tanah yang telah disebutkan, wilayah dengan fluktuasi air tanah pada tingkat tinggi layak mendapatkan perhatian khusus. Berkurangnya suplai air tanah karena perubahan musim bukan menjadi penyebab utama tinggginya fluktuasi air tanah di wilayah tersebut. Tingkat fluktuasi air tanah yang tinggi kemungkinan disebabkan oleh eksploitasi air tanah. Keberadaan lahan terbangun berupa fasilitas umum institusi pendidikan memicu munculnya lahan terbangun lainnya dengan peruntukan sebagai kos, tempat makan, tempat cuci kendaraan, tempat cuci pakaian, dan jenis usaha lainnya yang sangat mungkin menyebabkan penggunaan air tanah dalam jumlah besar. Munculnya lahan terbangun seringkali tidak disertai dengan upaya untuk menjaga air tanah agar tetap dalam kondisi yang baik. Lahan terbangun dengan permukaan lahan yang diperkeras menjadi penyebab menurunnya tingkat infiltrasi air hujan. Menurunnya tingkat infiltrasi berakibat pada berkurangnya cadangan air tanah, terlebih jika air tanah dieksploitasi. Permukaanan air tanah perlahan- lahan akan terus turun hingga air tanah pun semakin sulit didapatkan.
Berdasarkan Gambar 12, fluktuasi air tanah pada tingkat tinggi memang menempati proporsi luas yang paling kecil diantara tingkat fluktuasi yang lain. Namun perlu diketahui bahwa penurunan air tanah pada tingkat tinggi di suatu wilayah perlahan akan menyebabkan hal yang sama di tempat lain akibat terbentuknya cone of depression(21). Fenomena cone of depression (kerucut cekungan air tanah) menjadi bukti bahwa penurunan air tanah di satu tempat akan mengakibatkan penurunan muka air tanah di tempat lain. Terlebih jika tempat tersebut memiliki sistem akuifer yang sama.

Terdapat beberapa teknik yang dapat diimplementasikan untuk mengantisipasi semakin meluasnya fluktuasi air tanah pada tingkat tinggi, seperti pemanenan air hujan (rain water harvesting), pembuatan sumur resapan, dan pembuatan biopori. Pemanenan air hujan dilakukan dengan cara mengalirkan air hujan yang jatuh pada atap bangunan ke dalam tampungan (22-24). Air hujan tertampung tidak hanya dapat digunakan untuk mencukupi kebutuhan domestik, tetapi juga dapat digunakan sebagai sumber pengisian air tanah. Pengisian air tanah juga dapat dilakukan 
dengan membuat sumur resapan. Sumur resapan merupakan media untuk meresapkan air hujan yang jatuh di permukaan lahan(24). Seperti halnya pemanenan air hujan dan sumur resapan, pembuatan biopori juga dapat diimplementasikan untuk mengantisipasi permasalahan air tanah yang berkaitan dengan fluktuasi. Lubang biopori pada umumnya lebih kecil daripada lubang sumur resapan. Lubang tersebut pada dasarnya tidak hanya digunakan untuk meresapkan air hujan, tetapi juga sebagai media pembentukan kompos dari sampah organik $^{(24)}$.

Ketiga teknik yang telah diuraikan dapat diterapkan di daerah penelitian dengan mempertimbangkan kondisi fluktuasi air tanahnya. Pemanenan air hujan dapat diimplementasikan pada wilayah dengan tingkat fluktuasi tinggi, yaitu di Desa Umbulmartani, Desa Widodomartani, dan Desa Bimomartani. Ketergantungan terhadap air tanah dapat diminimalisir dengan air hujan yang telah tertampung. Wilayah dengan tingkat fluktuasi sedang dan rendah seperti Desa Wedomartani dan Sindumartani dapat menerapkan pembuatan sumur resapan dan bipori sebagai media peresap air hujan menjadi cadangan air tanah.

\section{KESIMPULAN}

Berdasarkan hasil yang telah dicapai diketahui bahwa fluktuasi air tanah pada jangka pendek di daerah penelitian diklasifikasikan menjadi tiga, yaitu fluktuasi tingkat rendah (kurang dari 2,5 meter), tingkat sedang (2,5 hingga 5 meter), dan tingkat tinggi (lebih dari 5 meter). Fluktuasi air tanah dengan tingkat rendah terdapat di Desa Widodomartani, Desa Wedomartani, Desa Bimomartani, dan Desa Sindumartani dengan luasan yang bervariasi. Fluktuasi air tanah dengan tingkat sedang terdapat pada seluruh desa di daerah penelitian dengan luasan yang juga beragam. Fluktuasi air tanah dengan tingkat tinggi hanya terdapat di Desa Umbulmartani, Desa Widodomartani, dan Desa Bimomartani. Eksploitasi air tanah menjadi faktor utama yang memungkinkan terjadinya tingginya fluktuasi air tanah di sebagian daerah penelitian. Penanganan terhadap masalah fluktuasi air tanah di daerah penelitian dapat dilakukan dengan meminimalkan eksploitasi air tanah dan memperbesar peluang air hujan terinfiltrasi menjadi cadangan air tanah pada wilayah padat pemukiman dan fasilitas umum. Wilayah dengan fluktuasi tinggi dapat menerapkan pemanenan air hujan, sedangkan wilayah dengan fluktuasi rendah dan sedang dapat mengimplementasikan pembuatan sumur resapan dan biopori. Peta tematik fluktuasi air tanah yang telah dihasilkan dalam penelitian ini dapat digunakan oleh dinas atau instansi terkait untuk menentukan zona prioritas penanganan masalah fluktuasi air tanah di Kecamatan Ngemplak, Kabupaten Sleman. Data kedalaman air tanah yang dipublikasikan dalam penelitian ini juga dapat dijadikan sebagai data awal untuk melakukan kajian lebih lanjut tentang fluktuasi air tanah pada jangka panjang di Kecamatan Ngemplak, Kabupaten Sleman.

\section{PERSANTUNAN}

Penulis menyampaikan terima kasih kepada Lembaga Penelitian Universitas Amikom Yogyakarta atas dukungan pembiayaan penelitian ini melalui Program Penelitian Hibah Internal Universitas Tahun 2019. Ucapan terima kasih juga penulis sampaikan kepada warga masyarakat di Kecamatan Ngemplak, Kabupaten Sleman yang telah memberikan izin dalam pengumpulan data penelitian.

\section{DAFTAR PUSTAKA}

1. Sejati, S. P., \& Adji, T. N. (2013). Kajian Potensi Airtanah di Lereng Selatan Gunungapi Merapi untuk Mencukupi Kebutuhan Domestik pada Hunian Sementara, (Magister Science Master Thesis), Universitas Gadjah Mada.

2. Asdak, C. (2014). Hidrologi: Gadjah Mada University Press.

3. Santosa, L. W., \& Adji, T. N. (2014). Karakteristik akuifer dan potensi air tanah Graben Bantul: Gadjah Mada University Press.

4. Sudarmadji. (2013). Pengelolaan sumberdaya air tanah terpadu: Gadjah Mada University Press.

5. Mishra, N., Khare, D., Gupta, K. K., \& Shukla, R. (2014). Impact of land use change on groundwater - a review. Advances in Water Resource and Protection, 2(2), 28-41.

6. Nagarajan, R., Thirumalaisamy, S., \& Lakshumanan, E. (2012). Impact of leachate on groundwater pollution due to nonengineered municipal solid waste landfill sites of erode city, Tamil Nadu, India. Iranian Journal of Environmental Helath Science and Engineering, 9(35), 1-12.

7. Utomo, A., Hendarmawan, \& Hadian, M. S. D. (2017). Karakteristik fluktuasi permukaan air tanah pada akuifer tidak tertekan di Kelurahan Cibabat, Kecamatan Cimahi Utara, Kota Cimahi. Jurnal Lingkungan dan Bencana Geologi, 8(3), 117-126.

8. Nugroho, N. E., Kusumayudha, S. B., \& Paripurno, E. T. (2019). Anomali perubahan 
muka air tanah di daerah urban. Jurnal Geografi, 16(1), 1-6.

9. Purwantara, S. (2015). Dampak pengembangan permukian terhadap air tanah di wilayah Yogyakarta dan sekitarnya. Geoedukasi, 4(1), 31-40.

10. Ramadhan, F., D.R., F. P., \& Adji, T. N. (2018). Kajian pencemaran airtanah di wilayah sekitar TPA Piyungan Bantul Yogyakarta. Paper presented at the Pertemuan IImiah Tahunan Ke-3 Perhimpunan Ahli Air Tanah Indonesia.

11.Sutardi, A., Suprayogi, S., \& Adji, N. (2017). Kajian kualitas airtanah bebas antara Sungai Kuning dan Sungai Tepus di Kecamatan Ngemplak, Yogyakata, Indonesia. Majalah Geografi Indonesia, 31(1), 31-38.

12. Sejati, S. P. (2017). Karakteristik sumber daya airtanah dangkal di Kecamatan Cangkringan Kabupaten Sleman Provinsi Daerah Istimewa Yogyakarta. Media Komunikasi Geografi, 18(2), 166-177.

13. Adji, T. N. (2007). Application of water table fluctuation method to quantify spatial groundwater recharge within the southern slope of Merapi Volcano, Indonesia. Indonesian Journal of Geography, 39, 151171.

14. Nayak, T. R., Gupta, S. K., \& Galkate, R. (2015). GIS based mapping of groundwater fluctuations in Bina Basin. Aquatic Procedia, 4, 1469-1476.

15. Badan Pusat Statistik Kabupaten Sleman (2019). Kecamatan Ngemplak Dalam Angka.

16.Dixon, C., \& Leach, B. (2015). Metode pengambilan sampel untuk penelitian geografi: Ombak.

17. Riasasi, W., \& Sejati, S. P. (2019). Potential of groundwater to supply domestic water necessity in evacuation shelters of Merapi Volcano eruption. Paper presented at the IOP Conference Series Earth and Environmental Science.

18. Adji, T. N., \& Sejati, S. P. (2014). Identification of groundwater potential zones within an area with various geomorphological units by using several field parameters and a GIS approach in Kulon Progo Regency, Java, Indonesia. Arabian Journal of Geosciences, 7, 161-172.

19.Li, J., \& Heap, A. D. (2008). A review of spatial interpolation methods for environmental scientists: Geoscience Australia.

20.Longley, P. A., Goddchild, M. F., Maguire, D. J., \& Rhind, D. W. (2015). Geographic information science and systems: John Willey and Son Inc.

21. Chen, J., Wu, H., Qian, H., \& Liu, Q. (2015). Analysis of evolvement for confined water cone of depression and its influence on groundwater resource sustainability in Yinchuan Area. Advanced Material Reserach, 1073, 1656-1659.

22. Ali, I., Suhardjono, \& Hendrawan, A. P. (2017) Pemanfaatan sistem pemanenan air hujan (rainwater harvesting system) di Perumahan Bone Biru Indah Permai Kota Watampone dalam rangka penerapan sistem drainase berkelanjutan. Jurnal Teknik Pengairan, 8(1), 26-38.

23. Harsoyo, B. (2010). Teknik pemanenan air hujan (rain water harvesting) sebagai alternatif upaya penyelamatan sumberdaya air di wilayah DKI Jakarta. Jurnal Sains \& Teknologi Modifikasi Cuaca, 11(2), 29-39.

24. Rofil, \& Maryono. (2017). Potensi dan multifungsi rainwater harvesting (pemanenan air hujan) di sekolah bagi infrastuktur perkotaan. Paper presented at the Proceeding Biology Education Conference. 